\title{
PATRIMONIO CULTURAL Y TURISMO EN TORNO AL CERDO IBÉRICO EN SALAMANCA ${ }^{1}$
}

\author{
Luis Alfonso Hortelano Mínguez* \\ Universidad de Salamanca \\ https://orcid.org/0000-0003-2507-5917 \\ Eduardo Azofra Agustín** \\ Universidad de Salamanca \\ https://orcid.org/0000-0002-9518-2374 \\ María Isabel Martín Jiménez* \\ Universidad de Salamanca \\ https://orcid.org/0000-0003-2859-0551 \\ José Ignacio Izquierdo Misiego* \\ Universidad de Salamanca \\ imisiego@usal.es
}

\section{RESUMEN}

Se analizan los vínculos del territorio con el Patrimonio Cultural generados a partir de la cría del cerdo ibérico, en un sistema agroecológico adaptado a las condiciones del medio natural conocido como monte hueco o dehesa, y de la elaboración de embutidos (en concreto el chorizo ibérico) a partir de la sabiduría popular. Este proceso, asentado en un largo devenir histórico de construcción de un paisaje agrosilvopastoril adecuado para una gestión sostenible del territorio, donde el cerdo ibérico juega un papel preponderante, y en las claves culturales transmitidas de generación en generación del modo de hacer embutidos derivados del cochino ibérico. Este modo de vida ha sido plasmado en pinturas, fotografías, folklore y textos literarios que demuestran las estrechas relaciones de las gentes salmantinas con su territorio, paisaje y costumbres y su valoración como recurso turístico-gastronómico.

Fecha de recepción: 14 de enero de 2019.

Fecha de aceptación: 16 de septiembre de 2019.

* Departamento de Geografía. Facultad de Geografía e Historia. Universidad de Salamanca. C/ Cervantes s/n. 37002 SALAMANCA (España).E-mail: sito@usal.es,imaji@usal.es,imisiego@usal.es

**Departamento de Historia del Arte. Facultad de Bellas Artes. Campus Ciudad Jardín. 37005 SALAMACA (España).E-mail: azofra@usal.es

1 La siguiente aportación representa los resultados del Proyecto de Investigación Territorio y Patrimonio Cultural: antecedentes históricos y arraigo tradicional de los embutidos del cerdo. El ejemplo del «Chorizo Ibérico de Salamanca», dentro de la «II Convocatoria de Proyectos de Investigación orientados a ofrecer soluciones al sector primario», organizada por la Universidad de Salamanca y con la colaboración de la Diputación Provincial y Caja Rural de Salamanca, 2017. 
Palabras clave: Turismo; patrimonio territorial; dehesa; gastronomía; cerdo ibérico; Salamanca.

\title{
The Iberian pig in Salamanca its role in cultural heritage and tourism
}

\begin{abstract}
Based on the breeding of Iberian hog in the Province of Salamanca, the relations between the territory and cultural heritage are analysed. Breeding conditions are well-adapted to the local ecosystem of pastureland with holm oaks, known as monte hueco or dehesa. Meat processing, for example the production of Iberian chorizo, is based on folk knowledge. The long historical past of pig rearing is embedded in a sustainable agro-sylvo-pastoral landscape and in a local culture related to the production of ham and sausages. This way of life is reflected in paintings, photographs, folklore and literary texts, which show the intense relationship of the people of Salamanca with their territory, landscape and traditions, as well as its asset as a touristic-gastronomic resource.
\end{abstract}

Keywords: Tourism; cultural heritage; dehesa; gastronomy; Iberian pig; Salamanca.

\section{EL PAISAJE AGRARIO FRUTO DE UN MODO DE VIDA SECULAR}

\subsection{Introducción}

A lo largo de estos dos últimos decenios, sobre todo en el periodo finisecular pasado, hemos asistido desde los ámbitos éticos, académicos y profesionales a una preocupación por el territorio que ha desembocado en una renovación conceptual y en una «nueva cultura territorial». El territorio ha dejado de ser un mero sustrato natural o espacio geográfico contenedor de componentes naturales y de elementos humanos y su concepto ha evolucionado hacia una construcción o «arquitectura territorial» con una raíz histórica o cultural. De este modo, el concepto de «patrimonio territorial» permite integrar, como construcción histórica, los elementos naturales y los componentes artificiales en lo que es la arquitectura del territorio histórico (Ortega, 1998). Se recoge así el legado acumulado durante siglos por el paso de las numerosas culturas que han dejado sus huellas a modo de precipitado, como si fuera un manuscrito o «palimpsesto». Las cicatrices antrópicas, con el devenir de los tiempos, se han transformado en un patrimonio común por la aceptación social como «herencia» o patrimonio y como testimonio valioso que reafirma la memoria colectiva y las señas de identidad. Ante el progresivo riesgo de destrucción y desaparición de los vínculos de la sociedad con el territorio ha surgido una corriente de preservación que se ha denominado «cultura del patrimonio».

En esta tesitura, se enmarca desde el punto de vista epistemológico el hilo conductor de este artículo al vincular el territorio y el patrimonio como garantes de un paisaje agrario único y excepcional (la dehesa) y de un producto agroalimentario tradicional derivado del 
cerdo ibérico (el chorizo ibérico) que aprovecha los esquilmos del monte hueco. Se parte de la comunión del modelo de explotación y gestión racional del monte abierto de quercíneas (encinas, quejigos, robles y alcornoques) y su utilización secular a partir del «saber hacer popular» con el objetivo de resaltar los elementos básicos del patrimonio territorial, su puesta en valor como recurso para el turismo y la necesidad de su conservación.

\subsection{La dehesa: un paisaje cultural vivo}

El emergente concepto de «patrimonio territorial» engloba tanto al patrimonio cultural tangible como al inmaterial sustentado en un territorio concreto habitado por una comunidad. En esta evolución conceptual la sociedad revaloriza el concepto de «paisaje», en su vertiente histórica y cultural de construcción humana que se debe gestionar (Convenio Europeo del Paisaje, Florencia 2000) ${ }^{2}$. Dentro de los paisajes, podemos identificar los paisajes naturales y los paisajes culturales como resultado del grado de intervención antrópica y de la simbiosis creada entre la naturaleza y las obras artificiales. En las tipologías de paisajes culturales, una muestra está constituida por los paisajes agrosilvopastoriles (la dehesa) que permanecen vivos en el tiempo porque la colectividad adquiere un compromiso social, económico y administrativo en línea con un modo de vida y con un proceso de desarrollo continuo.

Uno de los usos y aprovechamientos del monte hueco o adehesado es la alimentación de la cabaña ganadera porcina de la raza ibérica y, por tanto, el origen responde a condicionantes físicos y antecedentes históricos. La pervivencia de este paisaje agrario milenario y su entidad cultural pasa por la continuidad de los usos tradicionales de base social, económica y territorial. La cría del cerdo ibérico, mediante la montanera, contribuye a la preservación de la dehesa como equilibrio interterritorial, de revulsivo económico a partir de la industria chacinera y de cohesión social con las aportaciones a la cultura popular.

Con el paso de los años se ha generado un modo de vida ligado a la cría del ganado porcino ibérico, en concreto con el aprovechamiento de la montanera de la dehesa, y la transformación de la carne fresca en embutido, en especial, el chorizo ibérico. Estas particularidades del modo de vida se encardinan con la temática del patrimonio cultural inmaterial ${ }^{3}$ que reside en el imaginario colectivo de la provincia salmantina. Por ejemplo, en numerosos municipios los mozos y los quintos mantienen viva la costumbre festiva del «Cante del chorizo» o «Cantar el chorizo», en otros se celebra el «Día del chorizo» coincidiendo con la festividad de San Antón y, en muchos, se sigue con el rito tradicional de la matanza con el nombramiento del Choricero Mayor. Este poso cultural que sigue vivo, ha transcendido al folklore salmantino y los jóvenes cuando recorren las calles «cantando los chorizos» rememoran el pasado y abren el futuro a los niños con estos «cantos de ronda»: «No venimos por morcilla/ ni tampoco farinato;/ que vengo por un chorizo/ tan largo como el mi brazo».

2 Instrumento de ratificación del Convenio Europeo del Paisaje (número 176 del Consejo de Europa), hecho en Florencia el 20 de octubre de 2000 (BOE n ${ }^{\circ} 31$, de 5 de febrero de 2008).

3 Instrumento de Ratificación de la Convención para la Salvaguardia del Patrimonio Cultural Inmaterial, hecho en París el 3 de noviembre de 2003 (BOE $\mathrm{n}^{\circ}$ 31, de 5 de febrero de 2007).

Ley 10/2015, de 26 de mayo, para la salvaguardia del Patrimonio Cultural Inmaterial (BOE $\mathrm{n}^{\circ} 126$, de 27 de mayo de 2015). 


\section{LOS PAISAJES ADEHESADOS EN EL TERRITORIO SALMANTINO}

\subsection{Las características naturales del solar salmantino}

El perímetro de la provincia de Salamanca, con una extensión de $12.349 \mathrm{~km}^{2}$, resultante de la reforma territorial efectuada por D. Javier de Burgos en 1833 presenta unos grandes contrastes desde el punto de vista natural ${ }^{4}$. El solar salmantino localizado en el extremo suroccidental de la Comunidad Autónoma de Castilla y León se encuentra encorsetado por la raya hispano-lusa al oeste y los límites provinciales zamorano, abulense y cacereño desde el norte al sur siguiendo las agujas del reloj. La conformación de los términos municipales, fruto de los avatares históricos, ha fragmentado el territorio en 362 municipios que suponen desde el punto de vista administrativo una gran atomización. La necesaria agrupación comarcal para salvar esta compartimentación y realizar el estudio a una escala adecuada nos lleva a tomar como referencia las ocho comarcas agrarias nacidas del desaparecido Ministerio de Agricultura (1978) a partir de un criterio de homogeneización regulado por variables agronómicas: Alba de Tormes, Ciudad Rodrigo, La Fuente de San Esteban, Ledesma, Peñaranda de Bracamonte, Salamanca, La Sierra y Vitigudino. Esta delimitación comarcal en una provincia dedicada eminentemente a la agricultura y la ganadería es una referencia apropiada, teniendo en cuenta que Castilla y León no tiene comarcas establecidas y que la emigración y el vacío demográfico han terminado por desdibujar de la memoria colectiva algunas de las comarcas históricas y naturales (Llorente, 1980).

\section{Cuadro 1 \\ DATOS DE SUPERFICIE Y NÚMERO DE MUNICIPIOS DE LAS COMARCAS AGRARIAS DE SALAMANCA}

\begin{tabular}{|l|c|c|c|}
\hline Comarcas agrarias & Superficie (ha) & \% Superficie & Municipios \\
\hline Alba de Tormes & 123.430 & 10,00 & 45 \\
\hline Ciudad Rodrigo & 241.638 & 19,57 & 44 \\
\hline La Fuente de San Esteban & 143.001 & 11,58 & 30 \\
\hline Ledesma & 107.886 & 8,74 & 30 \\
\hline Peñaranda de Bracamonte & 91.023 & 7,37 & 26 \\
\hline Salamanca & 146.310 & 11,85 & 60 \\
\hline La Sierra & 145.272 & 11,76 & 71 \\
\hline Vitigudino & 236.233 & 19,13 & 56 \\
\hline Total & $\mathbf{1 . 2 3 4 . 7 9 3}$ & $\mathbf{1 0 0 , 0 0}$ & $\mathbf{3 6 2}$ \\
\hline
\end{tabular}

Fuente: Ministerio de Agricultura, Alimentación y Medio Ambiente. (2013)

4 Una síntesis de las características del medio natural provincial se puede encontrar en Tejero de la Cuesta, J. M. (Coord.) (1988). 
La mayor parte de la provincia salmantina se sitúa entre las isohipsas de los 700 y 900 metros y esta homogeneidad tan sólo se rompe al oeste por los hondos encajamientos o «arribes» del río Duero y de sus afluentes (Águeda, Tormes, Huebra, Las Uces, etc.), que se sitúan por debajo de los 700 metros, y en la zona montañosa meridional de las Sierras de Béjar, Francia y Gata que ascienden sus cotas por encima de los 1.000 metros. Por tanto, en el extremo noreste y en el centro preside una cierta regularidad definida por las planicies de la campiña y de la penillanura; mientras en el borde rayano la red fluvial ha labrado profundos tajos en la penillanura al aprovechar las fracturas y las fallas (con una cota mínima de 135 m en Vega de Terrón en La Fregeneda) y al sur las áreas montañosas con sus respectivos valles (2.443 m en El Trampal en Candelario y 380 m en el valle del Alagón) imprimen una mayor variedad morfológica al territorio provincial (ver mapa 1). Estas diferencias topográficas junto con un desigual sustrato geológico y litológico definen unas unidades de relieve que se superponen a las asociaciones de suelos, a las condiciones climáticas y a la cobertura vegetal para definir los paisajes del solar salamantino.

\section{Figura 1 \\ ESQUEMA ALTITUDINAL Y ADMINISTRATIVO DE LA PROVINCIA DE SALAMANCA}

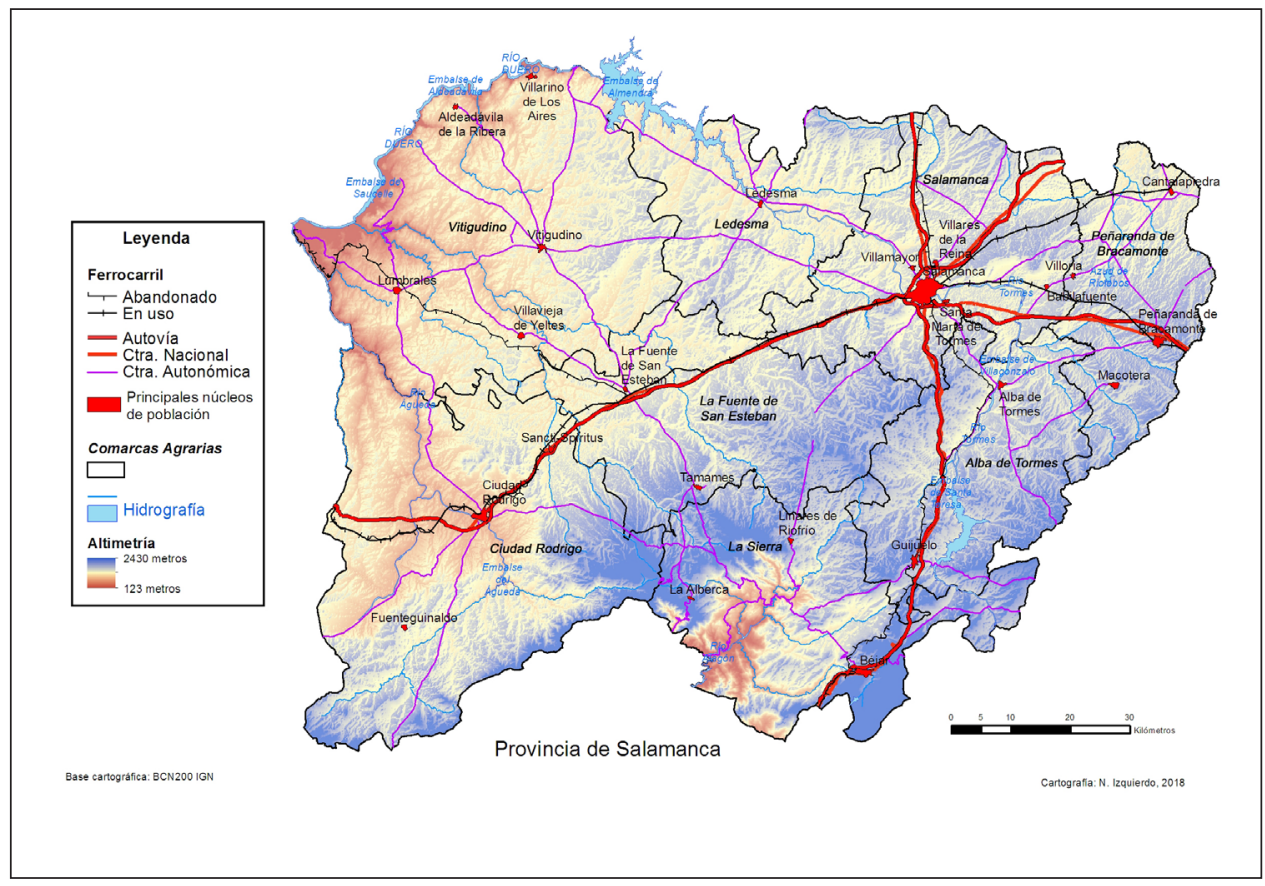

Desde el punto de vista geológico y geomorfológico, el soporte de la provincia está compuesto por el Macizo Hespérico que al fracturarse por los plegamientos alpinos levan- 
taron el cíngulo montañoso meridional y hundieron el extremo Noreste y Este - comarcas agrarias de Alba de Tormes y de Peñaranda de Bracamonte- rellenados con posterioridad con sedimentos en la Era Terciaria. En el resto de la provincia, excepto en las citadas planicies sedimentarias, la franja serrana y los cortados fluviales occidentales, aparece el zócalo de la penillanura exhumado o recubierto con una mínima capa de materiales sobre las rocas plutónicas (granitos) y metamórficas (pizarras y esquistos). La extensa penillanura está rasgada por una serie de pequeñas depresiones tectónicas con un trazado general de sus ejes NE-SO, denominadas genéricamente Fosa de Ciudad Rodrigo, rellenadas por materiales terciarios y cuaternarios.

Sobre estos materiales geológicos y los relieves resultantes, se sobreimpone la red hidrográfica superficial. Los principales ríos -Águeda, Huebra y Yeltes- tienen sus nacederos en la vertiente norte de los primeros escalones serranos salmantinos que atraviesan toda la provincia para tributar al Duero en el sector fronterizo. En la cara sur de la Sierra Mayor nace el río Alagón que vierte junto a sus afluentes Sangusín, Cuerpo de Hombre y Francia a la cuenca del Tajo. La otra arteria fluvial que recoge gran parte de las aguas provinciales es el Tormes, que desagua en el Duero en el paraje de Ambasaguas en el término de Villarino de los Aires, pero que tiene sus fuentes en la Sierra de Gredos y acumula las aguas del río Almar y de las Riveras de Cañedo y de la Valmuza. El resto de corrientes fluviales, pequeños arroyos y riveras, registran un caudal estacional y un aporte intermitente que ceden a los principales colectores de las cuencas del Duero y del Tajo.

La localización, las características del relieve y las referencias altitudinales de la provincia marcan unas condiciones climáticas de rasgos muy definidos mediterráneos con matices de continentalidad aunque en la franja occidental y al sur las influencias son atlánticas. La provincia participa de unas variables climatológicas mediterráneas, con una pronunciada sequía estival, que se adelgaza según nos desplazamos hacia el suroeste por la penetración de los vientos y frentes nubosos que elevan la humedad y reducen la oscilación térmica. En cuanto a las temperaturas, prácticamente toda la provincia presenta una temperatura media anual entre los $10^{\circ}$ y $14^{\circ} \mathrm{C}$, excepto las áreas microclimáticas de Arribes del Duero y del Valle del Alagón que superan $\operatorname{los} 16^{\circ} \mathrm{C}$ de media anual, con temperaturas mínimas entre los meses de diciembre y febrero y las máximas a partir de julio. Respecto a las precipitaciones totales anuales, se observa que oscilan de los $350 \mathrm{~mm}$ a más de $1.000 \mathrm{~mm}$ con un gradiente desde el noreste hacia el oeste y el sur coincidiendo con la entrada de los frentes atlánticos. La distribución anual de la pluviosidad es irregular con el mínimo en los meses estivales, sobre todo en agosto, y los máximos entre noviembre y enero. Este tránsito climático, también se observa en la provincia con el paso paulatino de vegetación esclerófila del noreste y centro a las manchas caducifolias del oeste y del sur.

Por último, la original cubierta vegetal natural se encuentra hoy en día intervenida por las roturaciones para incrementar la superficie labrada y por las repoblaciones como respuesta a los incendios y a las medidas de la política agraria. Estas acciones, han dado como resultado una situación heterogénea de la cubierta vegetal en la provincia. Las tierras del noreste (comarcas agrarias de Alba de Tormes, Peñaranda de Bracamonte y parte de la de Salamanca), en tiempos pretéritos ocupadas por montes de encina (Quercus ilex), en la 
actualidad son grandes extensiones de campos abiertos con orientación al secano cerealista favorecidos por la productividad de los suelos y, tan sólo, con un exiguo arbolado residual en la llanura y en las riberas de los ríos. En la raya con la provincia de Zamora, se localiza una zona ecotónica compuesta por un extenso monte de alcornoques (Quercus suber) acompañado de otras quercíneas. En dirección centroccidental, la veste vegetal, al hilo del aumento de las precipitaciones, transita de la encina al quejigo (Quercus lusitanica) y al roble melojo o rebollo (Quercus pyrenaica). Por último, en las áreas montañosas y el piedemonte del sur dominan los bosques de roble melojo excepto en los valles encajados, en las solanas y en las zonas repobladas de pinos. Como se deduce de este somero esquema de la vegetación, el predominio de los montes con especies de quercíneas es abrumador en la provincia y su presencia está relacionada no solo con las condiciones naturales sino sobre todo con un uso ancestral, que ha sabido conjugar explotación y conservación mediante el monte ahuecado o dehesa.

\subsection{El monte hueco o dehesa como forma de explotación agraria}

El monte hueco o dehesa constituye una de las muestras más representativas de los variados paisajes agrarios salmantinos y uno de los modelos de gestión agrosilvopastoril de mayor rentabilidad ecológica y económica reconocidos a nivel mundial (Gómez, 1991). Los espacios adehesados son el resultado de la roturación y desbroce del monte ciego o moheda original de encinas (Quercus ilex), quejigos (Quercus lusitanica), robles (Quercus pyrenaica) y, en áreas puntuales, alcornoques (Quercus suber) con el objeto de aprovechar el vuelo del árbol y el suelo con cosechas de cereal de secano o como herbazal para el ganado. Además de las parcelas rústicas, estas fincas cuentan con el casar como residencia del propietario y el resto de las dependencias para alojamiento de jornaleros y gestión de la explotación (graneros, paneras, pajares, corrales, plaza tentadero, etc.).

La dehesa salmantina tiene su origen en el acotamiento que se realiza de los espacios comunales que los repobladores medievales no ocupan para dedicarlos a montes. Los pobladores de la Edad Media de la zona central de la provincia eligen como lugares de asentamiento las riberas de los ríos por su disposición de agua y de espacio para cultivar y de pasto y reservan los interfluvios para terrenos montaraces. La debilidad del poder real y de los concejos permitirá la usurpación por parte de las clases altas y medias de estos terrenos o «cotos redondos» que logra perpetuarse a costa del desplazamiento de renteros, colonos y aparceros. El vocablo dehesa significa defensa e, incluso, en la Edad Media correspondía a prohibición porque estos predios estaban acotados (Cabo, 1978: 67). A lo largo de los siglos, esta propiedad se va a concentrar en manos de casas nobiliarias, órdenes eclesiásticas y hacendados rurales. En la actualidad, las grandes propiedades adehesadas o términos redondos con más de 50 ha están en manos de las familias que ya las poseían desde hace siglos, de la iglesia o en poder de nuevos propietarios y, aunque muchas han mudado la estructura del parcelario o se han dividido por herencias o por concentraciones parcelarias, mantienen su identidad paisajística. 


\section{Figura 2 \\ DISTRIBUCIÓN DE LOS ESPACIOS ADEHESADOS EN LA PROVINCIA DE SALAMANCA}

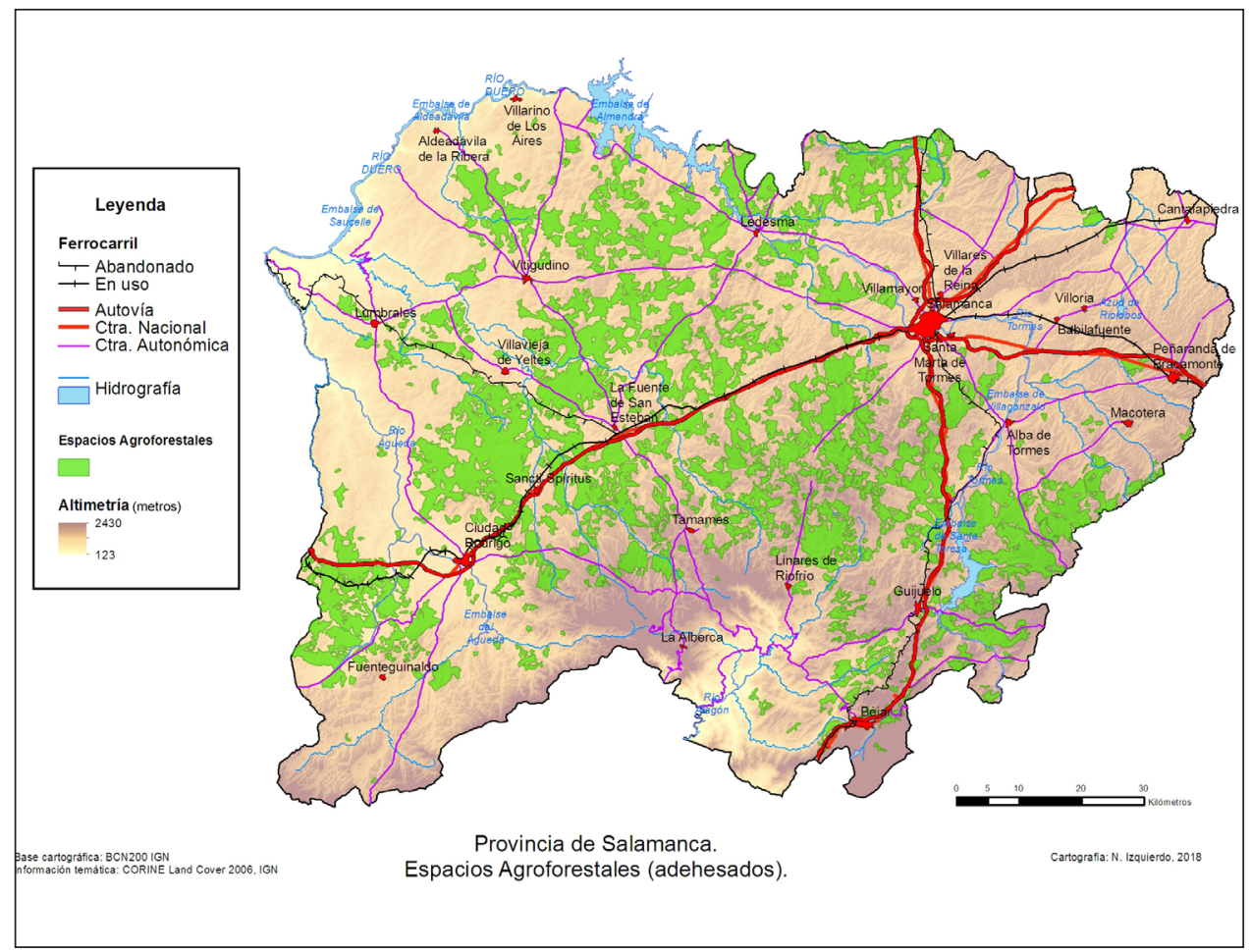

El modelo de explotación consiste en el desmoche del árbol para que las ramas en forma de candelabro se expandan en horizontal más que en vertical. Los beneficios de los cuidados forestales traen consigo la obtención de leña, madera (en ocasiones otrora para carboneo) y frutos para la montanera al tiempo que la copa aporta sombra a una amplia área de pasto para el ganado vacuno, lanar y porcino. El uso del suelo se destina a tierra de cultivo con rotaciones largas, un año de cada cuatro, y a pasto natural más fresco en primavera y otoño que se transforma en pastizal en el estío. Aunque la dehesa presenta un uso agrario y forestal, se identifica sobre todo con una cultura ganadera cuya finalidad principal es la producción de carne de una forma competitiva y de calidad asociada a grandes virtudes ecológicas. Por tanto, la orientación productiva de este agrobiosistema hay que buscarla en el mantenimiento de la ganadería autóctona o en la utilización de cruces industriales con el fin de conseguir productos de calidad.

Precisamente la cría del ganado en régimen extensivo es una seña de identidad en la dehesa salmantina, las diferencias las encontramos en la apuesta por el tipo de cabaña; en nuestro caso el objeto de estudio es el ganado porcino: el cerdo ibérico. 


\section{LA CABAÑA PORCINA EN SALAMANCA}

\subsection{Evolución de la ganadería porcina en Salamanca}

La cría de ganado en la provincia salmantina ha sido una constante a lo largo de los siglos como complemento a la economía de subsistencia de las familias en el medio rural y, en el tránsito finisecular del siglo XIX como actividad industrial. Dentro del hato ganadero familiar, el cerdo constituía un animal básico que garantizaba la alimentación de todo el año a través de la conservación de la carne mediante diversas técnicas tradicionales. La evolución de la cabaña ganadera salmantina, a partir del siglo XVIII, ha seguido la misma dinámica que en el resto de las provincias españolas. El descenso del censo ganadero a finales del siglo XVIII estuvo motivado por las luchas de los campesinos por agrandar la superficie cultivada con los rompimientos de baldíos y montes ciegos contra los boyeros, pastores y porqueros que veían menguar la superficie de herbajes (Klein, 1960). Entrado el siglo XIX, con la desamortización civil y eclesiástica se liberan ejidos y montes públicos destinados por los nuevos propietarios tanto a la roturación, que conlleva el crecimiento de las sernas cerealistas, como a la multiplicación de las cabezas de ganado de sus rebaños. La carga ganadera a finales de la centuria decimonónica se torna excesiva para la extensión de los aprovechamientos de pastos existentes y los efectivos pecuarios decaen. El balance de la ganadería porcina durante el siglo XVIII y XIX, según las fuentes históricas, se puede considerar oscilante con subidas y bajadas más acusadas en comparación al resto de las especies de ganado mayor (ovino, caprino, bovino y equino); recordemos que el incremento de las roturaciones beneficia a los animales de trabajo, los bueyes y el equino (caballar y mular), imprescindibles para el quehacer agrario.

El aumento de la población y del nivel de vida, entre finales del siglo decimonónico y la contienda bélica de 1936, influyen en la subida de la explotación pecuaria. Además de estos motivos, las conquistas agrarias propiciarán un significativo aumento de los recuentos de porcino a escala nacional. Posteriormente, las oscilaciones políticas y económicas con una fuerte inflación marcarán el retroceso del contingente ganadero tras la finalización de la guerra interior hasta 1959. De nuevo, el ganado porcino se muestra errante al decaer su proporción en el conjunto en la década de los años cuarenta frente a la situación de la anteguerra. Sin embargo, a partir de la mitad de la centuria pasada incidirá en la cabaña ganadera no sólo la demanda de productos cárnicos de la población de los grandes centros de consumo y el nivel de vida con la subida de salarios sino, también, las mejoras en las superficies dedicadas a la alimentación, los resultados de las cosechas, la disponibilidad de piensos y la llegada de razas alóctonas de gran precocidad. En este periodo, con el desvanecimiento del aislamiento económico crece la cabaña ganadera de la mano del uso generalizado de más alimento para los animales gracias a la culminación de las obras de regadío dedicadas a tierras maiceras y la importación de grano de cebada. La ganadería no se mantuvo al margen del desarrollo social y económico general que se manifiesta en cambios tanto en la composición como en los modelos de explotación. 
Además, desde la década de los sesenta de la centuria pasada, se introdujeron las razas mejorantes (Tolosa, 1998: 31 y 32) denominadas, según recoge el Catálogo Oficial de Razas de Ganado de España (Ministerio de Medio Ambiente y Medio Rural y Marino, 2010), como la Hampshire y la Poland China, aunque serán más utilizadas la Large White o gran cerdo blanco inglés, Landrace, Duroc o Duroc-Jersey que hoy en día están integradas en la cabaña ganadera salmantina.

Recurrimos a las palabras de Cabo Alonso (1960) para explicar la situación de las razas autóctonas y su cría en el momento de la llegada de las razas mejorantes. Señala que la principal es la Large White, que casi se limitaba a Cataluña, y añade:

«Mayor importancia tienen las célticas, que alcanzan el 14,2 por 100 y en las que algunos autores distinguen gallega, asturiana, vitoriana y navarra. Son en general corpulentas, magras y rentables. Se alimentan, en régimen de bastante estabulación, con maíz, castañas, coles, patatas y manzanas que, por su escasa calidad o tamaño, no encuentran fácil mercado, y también con pescado o harinas de él.

Predominan sobre todo las llamadas razas ibéricas, que campean por toda la Iberia seca y sobre todo en Extremadura, Andalucía y Salamanca y el resto de la submeseta sur, donde encuentran los mismos inconvenientes para su alimentación que las ovejas. La lechigada de raza ibérica no es buena; los animales llegan poco nutridos al destete. Se ha fijado como línea de separación con las célticas la diagonal que va desde la desembocadura del Miño hasta Valencia.

Unos ibéricos se dedican al recrío para el año siguiente, alimentados con acebuchina y ramón o compartiendo los rastrojos con las ovejas; otros pasan a los quince o dieciséis meses al cebadero, para el sacrificio posterior. De repente han de engrosar alli lo suficiente, con arvejas, guisantes, habas, garbanzos pequeños, cebada o trigo desnaturalizado. Para muchos es cebadero, o al menos etapa inmediata anterior a él, la montanera. Las bellotas de encina que alli consumen son ricas en hidratos de carbono, pero no en proteínas, que pocas veces pueden suplir con hierba abundante, frutos frescos o pescado. $Y$, de todas formas, estas alternancias bruscas de hambre y abundancia, y el esfuerzo que durante aquélla han de desplegar los animales en busca de alimento, dan lugar a ejemplares de corta talla, mucha osamenta y grasa excesiva, condiciones todas que implican también poco rendimiento.».

Con la llegada de las razas foráneas de capa blanca, la explotación del ganado de cerda comparte un sistema extensivo reservado a las piaras ibéricas, con aprovechamiento de la montanera de la encina, y un régimen intensivo de estabulación tanto para los cerdos de capa blanca como para los cochinos de ibérico de variedad retinta o colorada. No obstante, el cerdo ibérico criado en libertad siempre ha predominado en la provincia y se mantiene, pues según algunos autores ${ }^{5}$ es necesario por su rusticidad y para la explotación de las encinas a pesar de su rendimiento escaso en la producción de carne. El grado de rusticidad del cochino ibérico reside en su elevado grado de adaptación a la irregularidad de disposición de alimento (hierbas, cereales, leguminosas, bellotas, etc.) al alternarse periodos de abundancia con épocas de escasez.

5 Francisco García Zaragoza, Ingeniero de Caminos y delegado para Salamanca de la Confederación Hidrográfica del Duero, en la publicación del BANCO VIZCAYA. (1966). Salamanca y su desarrollo económico. Salamanca, Artes Gráficas Grijelmo, pp. 22-23. 


\section{Cuadro 2 \\ EVOLUCIÓN DEL NÚMERO DE CABEZAS DE PORCINO}

\begin{tabular}{|l|c|c|c|c|}
\hline Comarcas agrarias & $\mathbf{1 9 5 5}$ & $\mathbf{1 9 8 9}$ & $\mathbf{1 9 9 9}$ & $\mathbf{2 0 0 9}$ \\
\hline Alba de Tormes & 10.688 & 53.935 & 152.203 & 145.198 \\
\hline Ciudad Rodrigo & 17.751 & 33.553 & 74.296 & 50.427 \\
\hline La Fuente de San Esteban & 17.206 & 36.622 & 61.565 & 57.280 \\
\hline Ledesma & 8.062 & 13.465 & 22.566 & 58.010 \\
\hline Peñaranda de Bracamonte & 4.575 & 17.229 & 54.570 & 59.613 \\
\hline Salamanca & 13.558 & 24.112 & 55.073 & 69.901 \\
\hline La Sierra & 11,027 & 38.642 & 60.482 & 17.510 \\
\hline Vitigudino & 18.295 & 17.168 & 23.941 & 16.963 \\
\hline Total & $\mathbf{1 0 1 . 1 6 2}$ & $\mathbf{2 3 4 . 7 2 6}$ & $\mathbf{5 0 4 . 6 9 6}$ & $\mathbf{4 7 4 . 9 0 2}$ \\
\hline
\end{tabular}

Fuente: Instituto Nacional de Estadística. (INE). Censos Agrarios de 1955, 1989, 1999 y 2009.

Carecemos de datos diferenciados por razas, pero sabemos que las piaras de porcino en la provincia salmantina han crecido al pasar de 101.162 animales en 1955 a 572.224 animales en 2015, como muestra el Anuario de la Junta de Castilla y León (2017) ${ }^{6}$, y 597.491 animales en 2017 según la Encuesta Ganadera del Ministerio de Agricultura, Pesca y Alimentación. En el transcurso de estos años, según los datos de los censos agrarios de 1989, 1999 y 2009, la tendencia ha sido la creciente presencia de las cabezas de porcino en el registro del ganado mayor y, como en el pasado, ha registrado vaivenes y oscilaciones en el conjunto del total de cerdos.

Las cifras más elevadas se corresponden con las zonas de Vitigudino, Ciudad Rodrigo y La Fuente de San Esteban, aquellas donde las dehesas son más abundantes. En el transcurso de los años, la estabulación ha llevado a un aumento de cerdos en las comarcas con menores herbajes y así Alba de Tormes y Salamanca, que combinan dehesas con tierras de pan llevar, son en la actualidad las que tienen un mayor número de cabezas y, como antaño, el cerdo ibérico continua campeando por las dehesas del solar provincial.

\subsection{La cría del cerdo ibérico en la dehesa}

El cerdo ibérico de capa oscura, como ya hemos señalado, ayuda al mantenimiento del ecosistema de la dehesa y está bien adaptado por su elevada rusticidad y porque se alimenta de bellotas en régimen extensivo. El cerdo anda por la dehesa o más bien trota arqueando el lomo, sin seguir una línea recta, sino moviéndose en un zigzag continuo. Esta característica otrora llevó a referirse a esta raza como «camperos» y «malandares» y así lo refiere el diccionario de Pascual Madoz (1845-1850: 29, 58, 76 y 132) en numerosos pueblos; veamos algunos ejemplos:

6 Junta de Castilla y León. (2017). Anuario de Estadística Agraria de Castilla y León, 2015. Valladolid, Consejería de Agricultura y Ganadería. 
ABUSEJO: deh. En la provincia de Salamanca...se mantienen todo el año en la deh.: además se ceban en ella por un quinquenio 50 cerdos de vara y se sostienen 200 malandares.

ARMENTEROS:...rodea el térm. un monte de buen arbolado de encina que mantiene 100 cerdos de vara y 300 malandares.

BERROCAL DE SALVATIERRA: ... y en él se encuentra un monte que mantiene en un quinquenio 200 cebones y 800 malandares.

GALISANCHO: ... EL TERRENO es de superior calidad, aunque llano en su mayor parte tiene un monte de encina en el que se mantienen 50 cebones y 200 camperos.

\section{Figura 3}

\section{VAREADORES DE BELLOTAS}

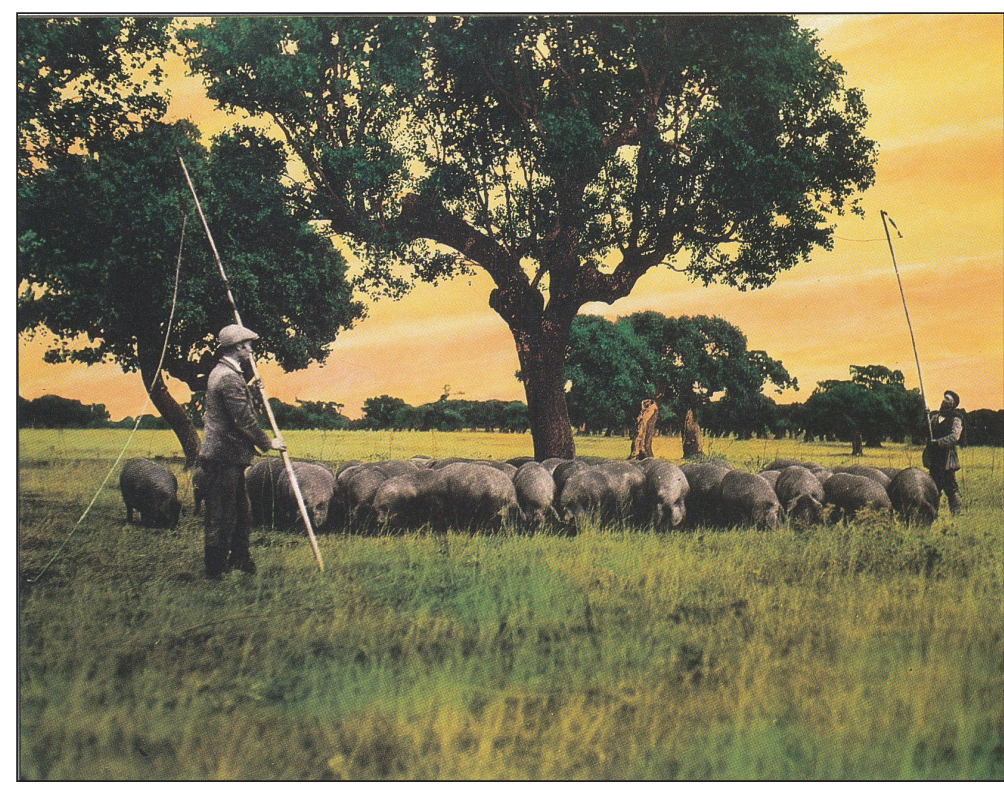

Fuente: Fotografía de Cándido Ansede. Fundación Tatane Ruiz Ansede. Coloreado manual con anilinas (Ruiz, 1992: 157).

El ecosistema de la dehesa ofrece a las piaras de cerdo ibérico una variada gama de esquilmos o recursos para su alimentación: hierba o pasto, rastrojos y bellota. Los herbajes de pasto natural o mejorado compuesto de gramíneas y leguminosas crece en los meses primaverales y en otoño aportarán gran cantidad de proteínas y vitaminas al animal. El aprovechamiento de las rastrojeras de los cultivos herbáceos tras la siega complementa la nutrición de los marranos. Por último, el fruto de las diferentes quercíneas (encina, quejigo, roble y alcornoque) representa el alimento indispensable en la dieta del cerdo ibérico que encuentra el punto maduro desde finales de septiembre hasta febrero dependiendo de las condiciones climatológicas. 
La alimentación a base de bellotas (Morales y Morales, 2000: 367), la denominada montanera, se empieza a planificar a primeros de septiembre con el alquiler de las dehesas y la adquisición de los primales, es decir, los cerdos aptos por peso y edad para entrar a comer el fruto de la encina, quejigo, roble y alcornoque. Este último árbol, produce tres tipos de bellota: las «migueleñas» por San Miguel (29 de septiembre), las «martinencas» por San Martín (11 de noviembre) y las «palomeras» o tardías en enero. Los animales primales cuentan con unos 90-110 kilogramos de peso y una edad entre 12 y 15 meses y estarán unos cien días comiendo bellota y hierba a partir de mediados de septiembre. Los cochinos ibéricos en este tiempo de montanera alcanzarán los 180-190 kilos, comiendo unos 10-12 kilos de bellota diarios, lo que da una media de 1.200 kilos de bellota por cerdo y la necesidad de contar con una hectárea de superficie por animal.

La montanera en la dehesa representa la última fase de la cría del cerdo ibérico para su engorde antes del sacrificio a través de un método de cebo natural y tradicional. Esta fase es fundamental según los ganaderos, porque la bellota con su elevado contenido en hidratos de carbono aporta energía y componentes ricos en grasa, almidón y azúcares, mientras las hierbas o pasto ayudan a digerir las bellotas y añaden el peculiar sabor a las chacinas, el principal aprovechamiento de la cabaña porcina ibérica.

\section{EL PESO DE LA TRADICIÓN EN LA ELABORACIÓN DEL EMBUTIDO DEL CERDO IBÉRICO}

\subsection{La matanza y el papel de los arrieros y choriceros}

El origen de la elaboración de embutidos (chorizo) y de chacinas en la provincia salmantina se puede rastrear en diversas fuentes escritas que hacen referencia a los aspectos industriales y las particularidades de la comercialización en diferentes lugares de la provincia; recurrimos a aquellos que hoy en día han aprovechado el saber hacer tradicional para convertirlo en una industria que ofrece un producto de calidad que aspira a ser reconocido como Indicación Geográfica Protegida7 ${ }^{7}$ En la villa de Guijuelo, como recoge el escritor José Mas $(1922)^{8}$, los cerdos se sacrificaban a lo largo de los primeros meses del invierno hasta el mes de febrero en la calle. Según la costumbre, en ese momento se realizaban las faenas del chamuscado, el raspado con la ayuda de agua y el destripado del animal para dar paso al despiece y el enfusado de las carnes picadas para el embutido. La matanza doméstica, hoy en día en retroceso, antaño servía para llenar la despensa con el fin de alimentar a la familia todo el año y como punto de encuentro para los parientes y vecinos del pueblo.

El caso de Candelario es otro referente ejemplarizante de su pasado industrial; de nuevo tomamos prestadas las palabras de otro autor para explicar el proceso de elaboración de las chacinas. Dice Salvador Llopis (1965: 144-145):

7 El chorizo ibérico ya tiene el reconocimiento de Marca de Garantía desde el año 2006 dentro de la Marca de Garantía "Ibéricos de Salamanca".

8 El escritor José Mas, en su novela El rastrero describe con realismo las conductas de los habitantes y las costumbres guijuelenses de aquella época de principios del siglo veinte. 
«el otro aspecto industrial de Candelario, es el ya conocido de chacinería y elaboración de embutidos, que le dio singular renombre y cuya antigüedad es anterior al siglo XVIII.

Explica Mesonero Romanos en "Memorias de un setentón", cómo tres dinastías: la de Peña, la de Rico y la de Bejarano llegaron a monopolizar de siglos atrás (y esto lo decía en 1882), el surtido de la Capital de España.

La elaboración de cecina y chorizo, adquirió un ritmo sorprendente, llegando en el siglo pasado -s. XIX-a la cifra de 8.000 cerdos sacrificados y 2.000 vacas cebadas ${ }^{10}$. La población entera se convertía desde Todos los Santos en un matadero público. Las matanzas se hacían en la misma calle al pie de cada casa; y todavía como vestigio efímero de la extinguida industria se descubren gruesos arrendaderos clavados junto a los portales utilizados para amarrar las reses antes de apuntillarlas. Para limpiar los regueros de sangre y el bandujo, corría el agua por las calzadas conducidas por acequias, agua de nieve precipitada desde El Calvitero. Las tareas se iniciaban a las cuatro de la madrugada con todo el carámbano en las fuentes.

Por el comienzo de siglo todavía se registraban sesenta casas choriceras. Cada matanza sacrificaba cuatro reses y para cada res cuatro cerdos; y como la costumbre era el de hacer dos matanzas a la semana resultaban que el cómputo total de animales sacrificados semanalmente ascendían a 1.920 cerdos y 480 vacas no menores en peso a cuarenta arrobas unidad (11,5 kilos). Todos estos datos dan idea de la magnitud de la empresa. Completaba, la acertada preparación de las carnes con fórmulas tradicionales, favorecida por la frialdad del clima permitiendo tener en las partes altas de las viviendas espaciosos secaderos y el sabor natural de las carnes cebadas principalmente con bellota dulce y castaña. En el término de Candelario se ven prados, algunos de más de sesenta peonadas, hoy invadidos por la zarza y el abrojo a donde se encerraban las tremendas piaras de cerdos "zorondos" (flacos), traídas de las renombradas ferias de Zafra, Plasencia y Salamanca, compradas por los choriceros ricos para el engorde.».

En la actualidad, el florecimiento industrial encuentra su fundamento en una mezcla de las técnicas artesanales legadas por los antepasados de generación en generación con la incorporación de los avances tecnológicos en el proceso de elaboración, secado y manipulado del embutido.

Junto a la matanza y a la transformación artesanal de las carnes, un papel transcendental en el origen y la consolidación de la industria chacinera en la provincia de Salamanca se debió a los arrieros, los trajinantes y los choriceros que llevaron los diferentes embutidos por la geografía nacional y difundieron la calidad de las chacinas elaboradas en Salamanca. Por ejemplo, los arrieros de la comarca de Guijuelo comercializaban los embutidos por toda la geografía española.

9 Nota del autor: Mesonero Romanos, Ramón de. (1926). Memorias de un Setentón, natural y vecino de Madrid / escritas por El Curioso Parlante. Madrid, Renacimiento.

10 Nota del autor: Tomado de Madoz, P. (1845-1850): Diccionario geográfico-estadístico-histórico de España y sus posesiones de ultramar. «...pero lo que más llama la atención en la ind. de este pueblo es la elaboración de cecina y chorizos que tanta fama llevan por la península, pues son en número tan considerable los que se hacen, que algunos años se matan al efecto 8,000 cerdos y 2.000 vacas gordas y cebadas». 


\section{Figura 4 \\ TIPOS SERRANOS ANTE LA CATEDRAL}

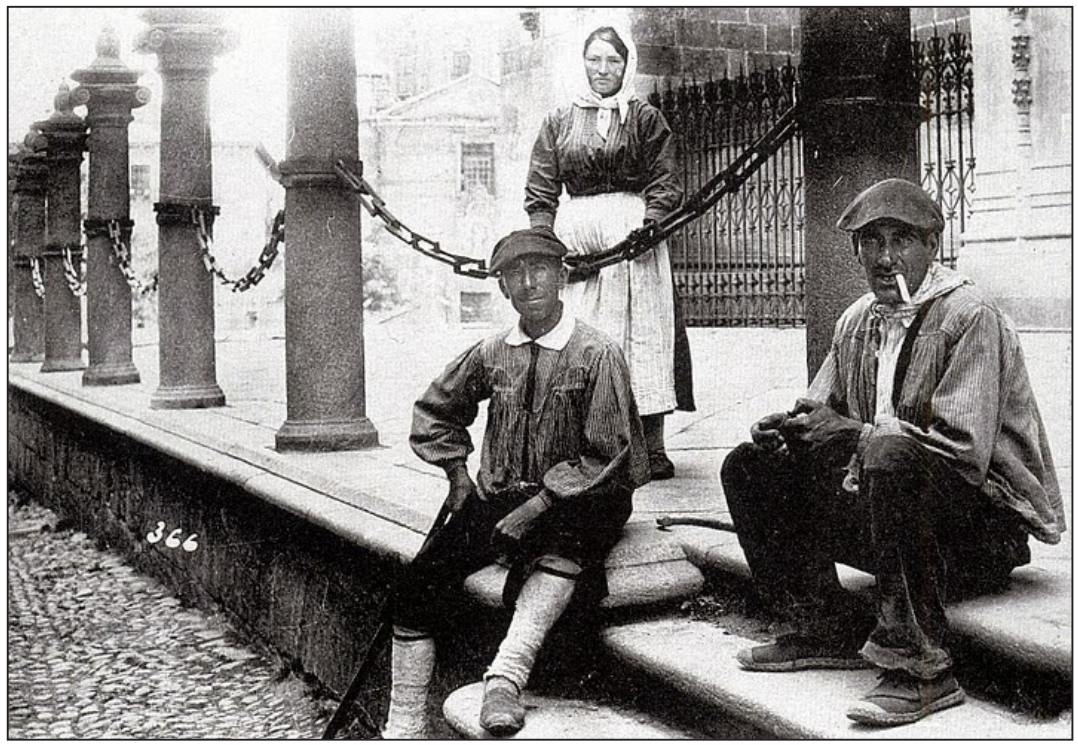

Fuente: Fotografía de Cándido Ansede. Fundación Tatane Ruiz Ansede. (Ruiz, 1992: 150)

Estos arrieros se desplazaron por tierras zamoranas, gallegas y el sur de Cataluña para mercar con los embutidos que cambiaban por tocino y jabones blancos. Los arrieros de Ledrada llegaron hasta La Mancha, en la provincia de Ciudad Real abrieron una sede temporal en Almagro, y otros se expandieron por Aragón y, más tarde, por Andalucía. El género se publicitaba para su venta, por ejemplo, el Diario de Avisos de Madrid del 1 de abril de 1830 recogía el siguiente anuncio «A la Cava baja, posada del Dragon, ha llegado un gran surtido de chorizos de superior calidad, fabricados en Salamanca de carne de cerdo sin otra mezcla, y embutidos en la misma tripa de cerdo, los que para su pronto despacho se han arreglado á los precios de 8 y $81 / 2$ rs. libra».

Con la modernización de la red de comunicaciones y de transportes por carretera y el desarrollo del tendido del ferrocarril a finales del siglo XIX, sobre todo la Línea Transversal Mérida-Palazuelos/Astorga que formará parte del Ferrocarril «Vía de la Plata», los arrieros con las reatas de carros tirados por mulos y los choriceros desaparecen para dar paso a la venta de embutidos a través de pequeñas tiendas y comercios. Las economías familiares adquirirán directamente los productos alimenticios del día a día, entre ellos el chorizo, en las tiendas de ultramarinos en las capitales provinciales y en el resto de los pueblos. Por su parte, los mataderos industriales y las fábricas de embutidos, de salazón de jamones, de tocino y demás productos del cerdo utilizarán estos nuevos medios de transporte (camiones y tren) más modernos y más rápidos en los desplazamientos para distribuir los géneros hasta los puntos de venta por toda la geografía nacional e internacional. 


\subsection{El proceso de elaboración del embutido: picado y enfusado de las carnes}

A lo largo de la historia, con la llegada de las heladas en el seno de las familias de las diversas comarcas salmantinas se ha realizado la matanza doméstica del cerdo para sacar las carnes frescas y elaborar los embutidos. Como ya hemos adelantado, a primera hora de la mañana, el matarife sacrificaba al cerdo y, posteriormente, se pasaba al chamuscado con la paja de rastrojo o helechos del río y se le abría en canal. Una vez que el cebón se quedaba frío, empezaba el despiece del animal, el descarnado de los huesos y el picado de la carne para que las mondongueras mezclaran el picadillo con la sal, el ajo, el pimentón de La Vera y las diversas especias. Las mujeres procedían con las máquinas al enfusado de la mezcla en las tripas para los chorizos y los salchichones que se colgaban en los varales. De este modo, las matanzas domésticas suponían un momento de reunión familiar y de vecinos alrededor de una costumbre milenaria.

Este ancestral rito popular ha decaído por numerosas causas pero el proceso de elaboración tradicional de embutidos derivados del cerdo ibérico se mantiene con las empresas de transformación cárnica. Las fábricas reciben el magro ibérico extra ya que el sacrificio de los marranos y el despiece con la eliminación de la grasa sobrante se efectúa en los mataderos acreditados. La carne y el tocino picados se aderezan con sal común, ajo, orégano y otras especias naturales, pimentón de La Vera y nitrificantes para pasar a las cámaras frigoríficas entre $0^{\circ}$ y $1^{\circ} \mathrm{C}$. Tras permanecer la mezcla adobada 24 horas en reposo, empieza el embutido de la mezcla en tripa natural que cuando es más gruesa recibe el nombre de cular. Posteriormente, los embutidos se trasladan al secadero artificial con temperatura controlada (entre $6^{\circ}$ y $8^{\circ} \mathrm{C}$ ) y una humedad del $75 \%$ durante 30 días con el fin de conseguir la ligazón de los trozos más grandes. Por último, los varales de embutido se llevan al secadero natural durante 2 meses y, tras finalizar este periodo, las piezas están listas para la colocación del etiquetado y la comercialización. Al corte el chorizo ibérico presenta un aspecto marmóreo con predominio del magro de color rojo vivo.

El poso de la tradición en la elaboración del chorizo en la provincia de Salamanca y la calidad del producto a partir del cerdo ibérico criado en la dehesa está exigiendo su reconocimiento, de Indicación Geográfica Protegida, como ya se ha apuntado, y, desde luego, estamos ante un patrimonio cultural, reflejado incluso en diferentes obras de arte, que se convierte en un recurso turístico y gastronómico para el disfrute de los embutidos y de la dehesa en la que deambulan las piaras de cerdos.

\section{LA EXPRESIÓN DE LA CULTURA POPULAR EN EL ARTE. APUNTES ARTÍSTICOS}

\subsection{Del cartón El Choricero de Candelario (h. 1786) de Ramón Bayeu a la estampa del Charcutier des montagues de Gata (h. 1860)}

Cuenta la tradición - una de las principales versiones está en el libro La vida en Madrid en 1886 (Sepúlveda, 1887)- que un día Carlos IV cazando por la sierra sintió hambre. Quiso el azar que por allí pasara un vendedor ambulante, cuyas mulas cargaban alforjas repletas de olorosos chorizos. Tío Rico -que era como llamaban a este choricero sus convecinos 
de Candelario-, ofreció al monarca su sabroso y oloroso embutido, y tal fue la satisfacción con la que el rey comió ese manjar que le convirtió en el proveedor de chorizos de la Casa Real, y el tío Rico y el chorizo de Candelario alcanzaron durante mucho tiempo gran fama en la Corte"1. Así, a comienzos del XIX en el Diario de Madrid se leía, "Ha llegado a la calle de Tudescos, casa $n^{\circ} 21$, Juan Rico, el que trae una partida de chorizos, jamones y sábanas de lienzo casero, con toda equidad"12, o en 1875 aún se vendían chorizos, jamones y morcillas en la Plaza Mayor de Madrid en un establecimiento llamado Rico (de la casa Rico, Fraile y Compañía, de Candelario) ${ }^{13}$, y en 1899 Manuel Alhama apuntaba en una revista que en una visita a Candelario le indicaron que "aquella que ve usted alli -me decían señalándome a una rubia muy bonita-, es de la familia de los Rico, fundada por el famoso tío Rico el choricero, cuyo retrato hecho por Bayeu figura entre los tapices del Pardo" (Wanderer, 1899: 4). En 1932, en la edición de Madrid del ABC de 5 de marzo, aún se insertaba un anuncio en el que se promocionaba la tienda del heredero del tío Rico, que había sido inmortalizado, aunque el dato era incorrecto, por Goya ${ }^{14}$.

En realidad, el autor de ese cuadro, el cartón titulado El choricero ${ }^{15}$, fue Ramón Bayeu, que lo pintó hacia 1786 a partir del pequeño boceto que su hermano Francisco incluyó en Trece bocetos para cartones de tapices, hoy en el Prado ${ }^{16}$. Se trata de una amable y colorista composición que sigue la tradición de las obras sobre vendedores ambulantes iniciada en Italia a comienzos del XVII por Annibale Carracci. El choricero, inspirado quizás en el tío Rico de Candelario, porta en su hombro izquierdo sus alforjas a medio llenar al haber optado, su condición de vendedor así lo requería, por mostrarnos el producto: los jamones de pata negra en el suelo, en primer plano, mientras lleva en su mano derecha varias sartas de chorizo ibérico, el embutido que tanta fama le dio. Viste el traje de su oficio: calzón corto y chaqueta de terciopelo gris, camisa blanca, chaleco de dos piezas, la exterior roja y la interior crema, polainas de paño negro y zapatos de igual color. Completa su atuendo, el frío arreciaba, un gabán de tono marrón, mientras cubre su cabeza con un gorro de paño negro animado con dos borlas o madroños.

El éxito logrado a nivel nacional y europeo por la serie de estampas Colección de Trajes de España -inspirada en Les cris de Paris-, que Juan Manuel de la Cruz Cano editó en 1777, sirvió de partida para otras imágenes donde los protagonistas eran tipos populares que encarnaban oficios y eran reconocibles fácilmente por su indumentaria; entre otras, la conocida Colección General de los Trages. Publicada en 1801, presenta 112 estampas (172 x $110 \mathrm{~mm}$ ) dibujadas por Antonio Rodríguez, grabadas al aguafuerte por él, José Vázquez,

$11 \mathrm{https} / / / \mathrm{blogs} .20 \mathrm{minutos} . e s /$ yaestaellistoquetodolosabe/tag/el-choricero/

12 https://www.nosabiasque.net/2009/05/traje-masculino-el-choricero-de.html

$13 \mathrm{https} / / / \mathrm{www}$.leonoticias.com/sociedad/gastrohistorias-tio-rico-choricero-majestad20180520191816-ntrc.html

14 http://www.nosabiasque.net/2010/02/rico-el-choricero-de-candelario.html. El anuncio decía: "Rico, el choricero de Goya. Sería grave pecado pasar por esta histórica barriada y no saludar a don Mariano Rico, descendiente del famosísimo Rico, el choricero de Candelario, que inmortalizó Goya Lucientes en uno de sus más notables tapices. Aún esta casa, Conde de Romanones, 12, sigue dedicada a la venta de sabrosos jamones, suculentos chorizos de Candelario y almacén de salchichería. Pueden hacer sus compras llamando al teléfono 74249".

15 Óleo sobre lienzo, 222x106 cm. Fuente: https://www.museodelprado.es/coleccion/obra-de-arte/elchoricero/47a56742-b51d-43c0-bf7d-7c3064affb1d

16 Óleo sobre lienzo, 45x96 cm. Fuente: https://www.museodelprado.es/coleccion/obra-de-arte/trece-bocetos-para-cartones-de-tapices/f90ba21a-d0f9-4049-b126-1531c08007b1 
Francisco de Paula Martí y Manuel Albuerne, e iluminadas con aguada de colores. El autor adjudicó al choricero a la región de Extremadura ${ }^{17}$, mientras que en Salamanca incluyó a un aldeano ${ }^{18}$. Hacia 1860 Clement Fréres editó en París la serie Collection de Costumes des diverses provinces d'Espagne ${ }^{19}$. Las ilustraciones, de gran calidad y coloreadas, en la parte superior presentaban el nombre de la región y el número de la serie, y en la inferior el oficio del personaje y su lugar de procedencia. Así, la $\mathrm{N}^{\circ} 46$, alusiva a la Región de Extremadura $^{20}, R^{e}$. de Estramadure, está dedicada al Charcutier des montagues de Gata / Choricero de la Sierra de Gata ${ }^{21}$. Este choricero, sentado en una gran piedra y que ha dejado en el suelo las alforjas llenas de viandas, viste de manera similar al de Candelario, al de los Bayeu. En definitiva, la fama de los chorizos, de los embutidos, salmantinos se había hecho extensiva a los extremeños en la segunda mitad del XIX, habiendo llegado hasta Francia.

Esta indumentaria tan característica de los choriceros de Salamanca, y de Extremadura, y la necesidad de salir a vender de manera ambulante, como trajinantes, vociferando por las calles sus embutidos a otros lugares (en algunos casos bien alejados, pero en otros no tanto, como se aprecia en el cuadro En la venta ${ }^{22}$, de Agustín Segura Iglesias), se mantendrá en las primeras décadas del siglo XX, perviviendo hasta esas fechas su aspecto inconfundible definido por cargar al hombro con las alforjas repletas de chorizos y la romana y llevar colgados los lomos del brazo y de la mano, como se advierte aún en fotografías de comienzos del siglo XX.

\subsection{El grabado, la pintura costumbrista y la fotografía como fuentes documentales. El cerdo ibérico protagonista en las ferias y mercados en las décadas finales del siglo XIX y primeras del XX}

Las evocadoras imágenes feriales -sean grabados, pinturas o fotografías-, nos transmiten los valores culturales de las ferias ganaderas y de los mercados semanales y cotidianos de los siglos pasados, lugares de convivencia y entendimiento. Con el paisaje monumental de Salamanca como telón de fondo, las ferias y los mercados ganaderos transcurrieron históricamente en la ciudad del Tormes junto al Puente Romano, a ambos lados del mismo, en la margen izquierda del río, alejados de los principales escenarios urbanos, en el Arrabal del Puente, en el Teso de la Feria, y con el puente como paso obligado de los numerosos carros cargados de mercancías que aquí llegaban y que desde aquí partían, como reflejó

17 https://www.museodelprado.es/coleccion/obra-de-arte/choricero-de-extremadura/8ad33ebf-ea7a-4ebe$8779-596 \mathrm{c} 53 \mathrm{c} 15 \mathrm{db} 4$

18 https://www.museodelprado.es/coleccion/obra-de-arte/aldeano-de-las-cercanias-desalamanca/4b125304-30b7-4b76-9e51-3c19724c8809

19 Las estampas (185 x 150 mm de mancha), dibujadas por el ilustrador Paul Hadol, que firmaba bajo el seudónimo de White, a partir de pinturas de Pigal, fueron impresas por el litógrafo Langlumé.

20 https://www.todocoleccion.net/arte-litografias/pigal-charcutier-des-montagnes-gata-choricero-sierra-gata-caceres-lit-langlume x38371402\#sobre_el_lote.

21 Cabe señalar que la Sierra de Gata marca el límite administrativo entre las provincias de Cáceres y Salamanca.

22 http://www.arcadja.com/auctions/es/segura_iglesias_agust\%C3\%ADn/artista/37975/ 
Harry Fenn en The bridge of Salamanca ${ }^{23}$. La estampa (265 x 192 mm), de gran calidad técnica, fue grabada en matriz de acero por John Godfrey en $1875^{24}$. El éxito inmediato alcanzado llevó a la editorial inglesa Cassell, Petter y Galpin a publicar entre 1876 y 1879 , y con idéntico título, ediciones más amplias y lujosas con láminas coloreadas, entre otras The bridge of Salamanca, aunque el rigor y la riqueza de información fueron sustituidos por lo anecdótico. En palabras de Conrad Kent, "la difusión en esos años del libro en varios idiomas es un hito clave en la evolución y difusión del costumbrismo anglosajón en la representación de Salamanca" (Kent, 2008a: 36).

Quizás Feria de ganado en Salamanca ${ }^{25}$, cuadro de Francisco Iturrino de 1898, sea el primero en el que un pintor atrapó con sus pinceles las ferias y mercados ganaderos celebrados en Salamanca. Con el cautivador perfil monumental de Salamanca al fondo, en el que destacan las catedrales, y con el Puente Romano en primer plano, Iturrino captó a la perfección el significado que las ferias y mercados de ganado tenían para la ciudad del Tormes. El pintor nos acerca la imagen de un mercado en frenética y "controlada" actividad. Multitud de personas, muchas ataviadas con los típicos trajes charros, y numerosas cabezas de ganado, destacando las piaras de cerdos ibéricos que invaden "ordenadamente", sin dejar ni un solo espacio libre, la ribera del río. Como es bien sabido, uno de los temas más repetidos del costumbrismo decimonónico fueron las ferias y los mercados, para algunos ambientes refractarios a la modernidad, que tanto llamaron la atención de los artistas extranjeros y nacionales. Y llegados aquí, ¿Iturrino representa la realidad que vio o la interpretación que hizo de ella? ¿Nos da su visión de artista de esa realidad o una reproducción fotográfica? ¿Los personajes y el ambiente son reales o el producto del genio creador del artista? Sin duda, Iturrino vio la escena, levantando testimonio de una costumbre que tal vez creyó en peligro de desaparecer, pero al hacerlo cabe suponer que lo hizo interpretando desde su perspectiva personal la realidad que veía, sentía y oía. Así, como ya apuntara Gómez Pellón (2005), "es posible que cuanto nos transmite sea, más que la realidad que ve, la que particularmente siente o, tal vez, la que voluntariamente pretende transmitirnos".

Y detrás del colorido y el pintoresquismo del cuadro de Iturrino hay también más información; por ejemplo, que durante las últimas décadas del siglo XIX, y en la primera mitad del XX, el ganado porcino de la feria y los mercados de Salamanca era siempre de raza ibérica, como se aprecia en esa maravillosa fuente documental que son las fotografías antiguas (Kent, 2008b: 61 y 74).

En este apartado tienen un lugar destacado las tomadas en la década de los 20 por el fotógrafo salmantino Cándido Ansede. Partiendo de la tradición costumbrista, se centró en el contexto y en la actividad de los personajes. En sus fotografías grupos de ganaderos reunidos, hablando, tratando, se mezclan con las piaras de animales, de cerdos ibéricos,

23 Se trata de una composición pintoresca de gran complejidad y cargada de sutileza a la que se asoman una serie de tipos costumbristas tratados con rigor, y que Fenn dibujó en 1873 durante el viaje que hizo por Europa con el fin de participar en la obra Picturesque Europe, libro editado en Nueva York entre 1875 y 1879 con grabados de distintos artistas

24 http://www.saber.es/web/biblioteca/libros/estampas-de-ferias-mercados-siglos-xviii-xx/html/imagenes/ enlace/img69.htm

25 Colección/Museo Carmen Thyssen-Bornemisza. https://www.carmenthyssenmalaga.org/obra/feria-deganado-en-salamanca 
cuidadas, vigiladas, por varias personas. Ansede logró, gracias a su perspicaz ojo y extraordinaria técnica, crear composiciones muy narrativas, apoderándose la vida cotidiana del escenario en el que transcurría, aunque éste fuera el paisaje monumental de Salamanca; "con agudeza e ingenio, elevó la instantánea a un nivel de gran elegancia estética y amplio valor documental” (Kent, 2008b: 105).

\section{Figura 5 \\ FERIA DE GANADOS EN LA RIBERA DEL PUENTE}

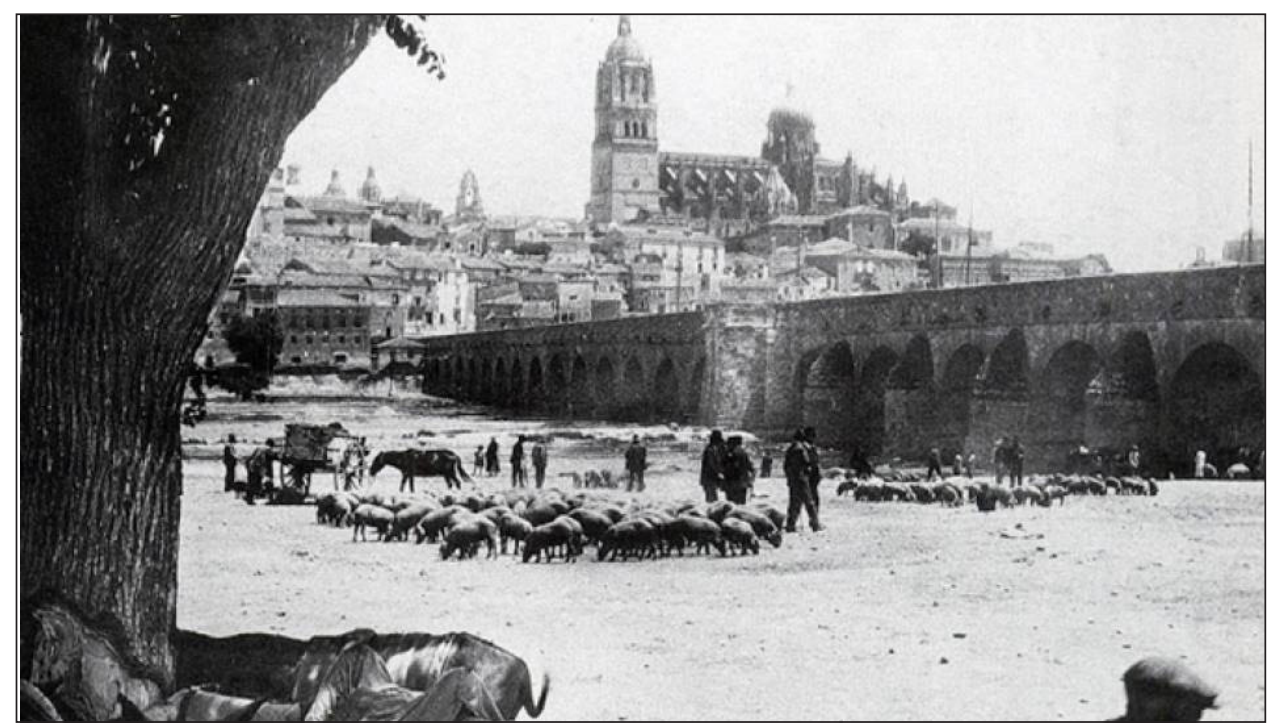

Fuente: Fotografía de Cándido Ansede. Fundación Tatane Ruiz Ansede. (Ruiz, 1992: 151)

Y para cerrar este apartado, dos dibujos estampados tipográficamente $(275$ x 380 mm de mancha), de los cuatro que el acuarelista y aguafuertista escocés Muirhead Bone publicó sobre Salamanca, y que Kent considera «la apoteosis anglosajona de la vista de Salamanca antes de la Guerra Civil» (Kent, 2008a: 41). Bone, reportero gráfico en las guerras mundiales y que en 1909 visitó por vez primera España, realizó los dibujos durante su visita a la ciudad en la feria de septiembre de 1926, si bien se dieron a conocer en 1936 con la publicación en Londres de una edición limitada de 266 ejemplares del inolvidable libro de viajes Old Spain $^{26}$, en el que los delicados textos que acompañan las imágenes fueron escritos por su mujer Gertrude. Los dibujos de Bone, obras de gran maestría técnica realizadas con ágiles y rápidos rasguños, reflejan magníficamente el ambiente ferial de la Salamanca de las primeras décadas del XX. En ambos dibujos panorámicos, que son dos soberbias escenas mercantiles, plasma con gran fuerza expresiva, estética

26 En 1938 publicaron una versión divulgativa titulada Days in Old Spain, de la que existe una versión española: Divagaciones por Castilla y León. Edición, traducción y notas de Álvaro Alcántara y Antonio Giménez Cruz, Ed. Junta de Castilla y León, Fundación Joaquín Díaz y Galería Frame, Valladolid, 2005. 
agreste y un evidente realismo a los hombres, mujeres y animales que invadían la ribera del Tormes los días de ferias y mercados semanales. Bone, como notario de la realidad que era, "es incapaz de inventar algo que no esté en su visión inmediata del paisaje o de los tipos que está retratando» (Diaz, 2005). En The Old Cathedral, New Cathedral and the Roman Bridge ${ }^{27}$ el Puente Romano se convierte en el marco perfecto que acoge la bulliciosa escena ganadera que transcurre en el abarrotado mercado de un día de feria. Dos numerosas piaras de cerdos ibéricos se han apoderado del primer plano, mientras que las cuadrillas de ganaderos, seguidas por otras piaras, van extendiéndose por la orilla del río Tormes. A su vez, el ciclópeo y sólido puente, por el que transitan jinetes, caminantes y carretas, sirve de base al maravilloso paisaje monumental que se despliega sobre el horizonte. Precioso escenario de la actividad ganadera de la ribera. El fondo monumental de la ciudad de Salamanca pierde potencia en Summer fair in the bed of the Tormes ${ }^{28}$, al no poder compensar la Peña Celestina, el Colegio del Rey y el barrio de Curtidores, a pesar de su precisa definición, la ausencia de las catedrales, de la espadaña de la capilla de la Universidad y de las torres y cúpula de La Clerecía. En este caso Bone opta por plasmar en todo su esplendor el mercado, la feria, y a sus protagonistas, a la multitud de personas y animales (una vez más, los cerdos ibéricos), que se dispersan por la ribera tormesina. En ese proceso de eliminación de los referentes arquitectónicos, Bone incluso evitó el Puente Romano, enmarcando en esta ocasión la escena con dos grandes acacias, con el deseo fundamental de potenciar el ambiente agrario y ganadero de la ribera izquierda del Tormes, algo que, por cierto, consiguió.

\section{LAS NUEVAS ACTIVIDADES: TURISMO GASTRONÓMICO, FERIAS Y CENTROS DE INTERPRETACIÓN}

Las ferias de ganado, la semanal los lunes y la anual por septiembre, se han mantenido. Ha cambiado la ubicación, la presencia de animales o las formas de hacer los intercambios pero Salamaq y su exposición de ganado puro es en la actualidad un referente en el calendario de ferias ganaderas en España y la principal para el ganado porcino ibérico junto con la feria internacional ganadera de San Miguel en Zafra (Badajoz) ${ }^{29}$. Al sentido tradicional de la feria para los profesionales del campo se han sumado en los últimos años otras actividades y una variada oferta expositiva, con propuestas de ocio en torno a la agricultura y la ganadería o degustaciones de especialidades gastronómicas, que convierten a la feria de septiembre en un atractivo turístico; en 2018 por el recinto de la feria pasaron más de 100.000 personas $^{30}$.

De igual manera, la cría extensiva y la industria agroalimentaria asociada con el cerdo ibérico se ha transformado recientemente en un renovado recurso turístico, dentro de la

27 http://www.saber.es/web/biblioteca/libros/estampas-de-ferias-mercados-siglos-xviii-xx/html/imagenes/ enlace/img97.htm

28 http://www.saber.es/web/biblioteca/libros/estampas-de-ferias-mercados-siglos-xviii-xx/html/imagenes/ enlace/img98.htm

29 El calendario de ferias ganaderas en España puede consultarse en http://www.interempresas.net/Ganadero/Ferias/

30 Tomado de la edición en papel del Norte de Castilla de 11 de septiembre de 2018; también puede consultarse en https://www.elnortedecastilla.es/salamanca/salamaq-cierra-edicion-20180911111028-nt.html 
modalidad del turismo gastronómico, por la perfecta comunión entre el modelo de producción y el proceso tradicional de elaboración de los embutidos. La provincia salmantina, desde el siglo pasado, ha recibido visitantes en busca de la calidad de los derivados del cerdo ibérico con la finalidad de degustar y de comprar chorizo, salchichón, lomo y jamón. De regreso a su residencia, los viajeros adquirían piezas ibéricas en las carnicerías de la ciudad como un souvenir más, hoy imprescindible, de tal forma que se ha incrementado la venta de perniles y de loncheados de chacinas.

A la atracción por las excelencias gastronómicas, se ha unido un interés por conocer otros pormenores de la vida del cerdo ibérico a través de la visita a los centros museísticos o mediante la participación en alguna actividad chacinera. En cuanto a los museos, la provincia cuenta con varios Museos Etnográficos o Centros de Interpretación con alguna sala dedicada a la matanza del cerdo o a la dehesa y, de forma monográfica, existe el Museo Casa Chacinera en Candelario y el Museo de la Industria Chacinera en Guijuelo; las dos villas con mayor tradición y actividad fabril en torno al cerdo ibérico.

La Casa Chacinera se ubica en el conjunto histórico de Candelario en una típica casa bloque con la doble función de vivienda y de fábrica dispuesta para la elaboración y secado de los embutidos. Esta casa-museo matancera, inaugurada en el año 2008, recrea en las dependencias las distintas fases de la matanza y el curado natural de las carnes mediante una ambientación a partir del empleo de enseres originales cedidos por los vecinos. El recorrido por la casa incluye una recreación teatralizada de la matanza en Candelario a principios del siglo XX que facilita la comprensión del propio museo.

\section{Figura 6 \\ MUSEO CASA CHACINERA EN CANDELARIO Y PIARA DE CERDOS EN LA MONTANERA (CESPEDOSA DE TORMES)}

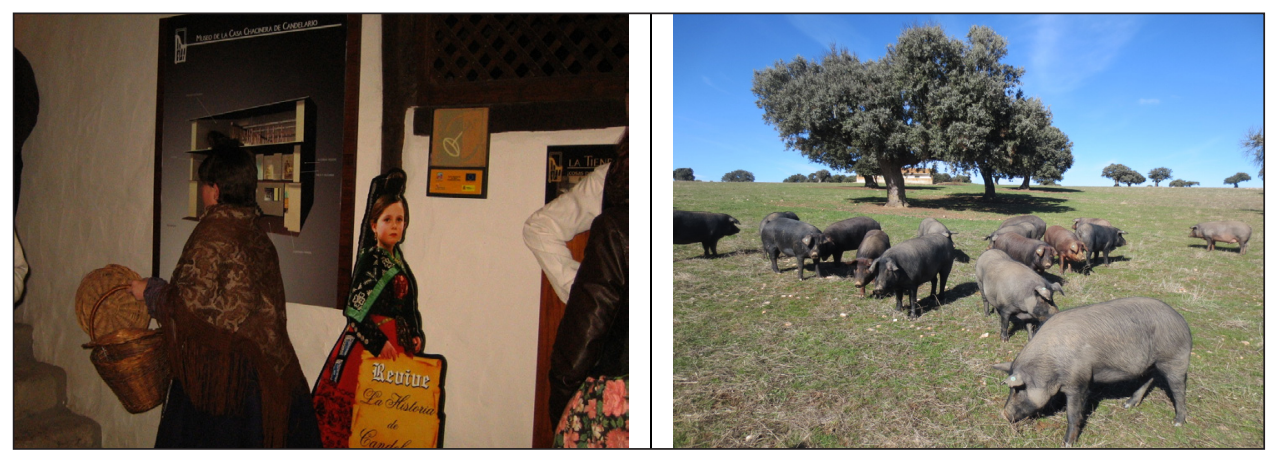

Fuente: Fotografías de Ma Isabel Martín Jiménez.

En cuanto al Museo de la Industria Chacinera de Guijuelo, que inició su andadura el 23 de enero de 2009, se emplaza en un edificio municipal en el centro de la villa. La muestra recoge en varias estancias la actividad chacinera de Guijuelo desde sus orígenes hasta el siglo XXI con el apoyo de objetos y de vídeos. La colección de utensilios ha crecido gracias a las donaciones desinteresadas de particulares y de empresarios hasta 
alcanzar más de 150 utensilios. Según los datos publicados por el museo, en estos diez años han contabilizado 35.496 visitantes, tanto individuales como en grupo, con el objeto de conocer de primera mano la evolución chacinera. Además, el museo ha ampliado su orientación con la organización de todo tipo de eventos y la participación activa en los proyectos «Gastronomía y territorio», junto al Grupo de Acción Local Adrecag, y «Salamanca Experience» de la mano de la Diputación Provincial.

Como complemento a los centros, se ofrecen recorridos a los visitantes que quieran adentrarse en los paisajes adehesados donde campean y engordan los cochinos ibéricos durante la campaña de la montanera y otros en los que puedan vivir en primera persona el ritual de la matanza típica. A las históricas Jornadas de la Matanza Típica de Guijuelo, este año se cumplieron XXXIV ediciones, la Diputación Provincial ha puesto en marcha un ciclo de Fiestas Tradicionales de la Matanza por toda la provincia. En la tercera campaña 2018-2019 (desde octubre a marzo), han participado treinta municipios en el circuito matancero. Los objetivos que persigue la iniciativa consisten en la dinamización socioeconómica de las comarcas rurales y la desestacionalización de la oferta turística en la temporada baja. También, desde el año 2017, la Diputación Provincial organiza el Día de la Montanera, con la distinción de Montanero Mayor, con la finalidad de dar visibilidad a la cultura del cerdo ibérico.

\section{Figura 7 \\ FIESTAS DE LA MATANZA Y MUSEOS EN LA PROVINCIA DE SALAMANCA}

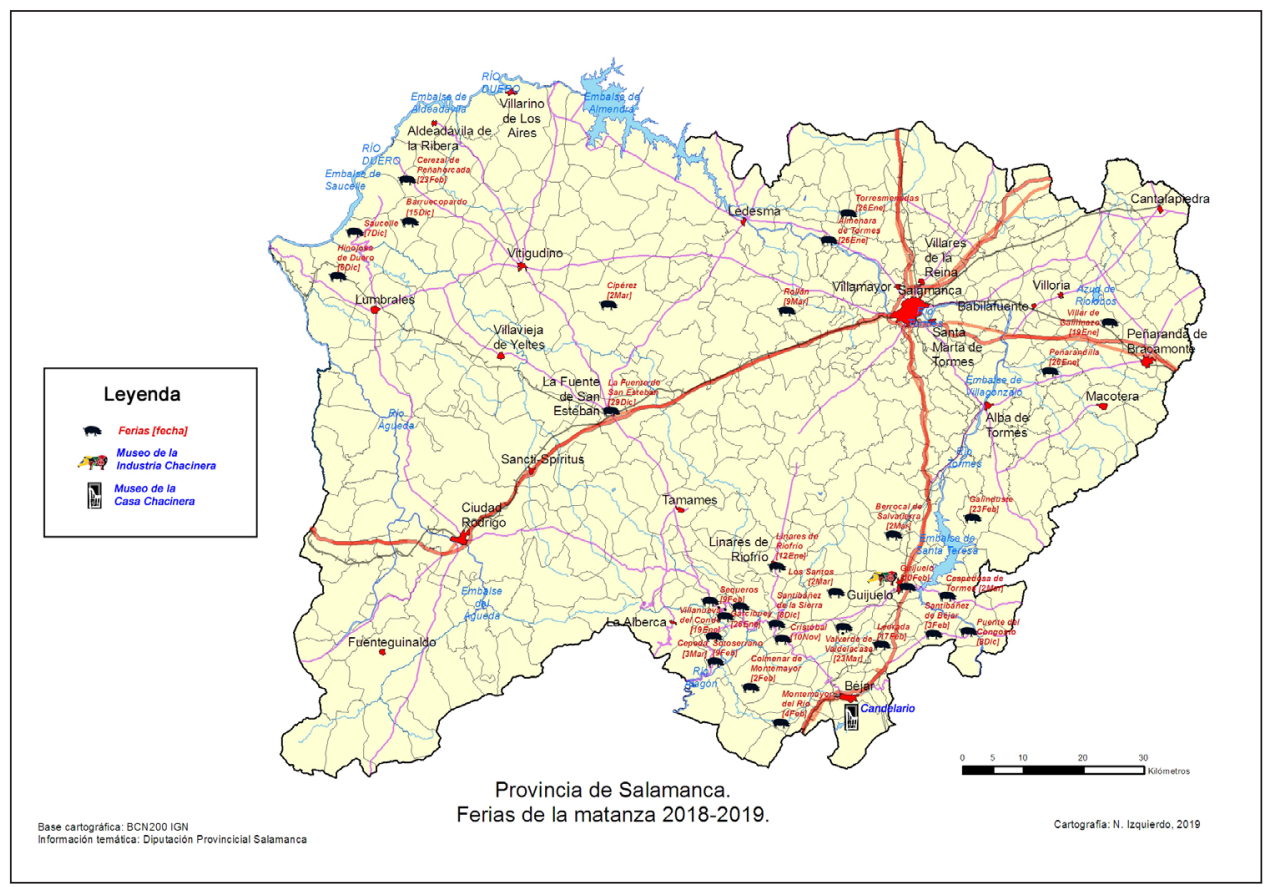


De cara al futuro, el Ayuntamiento de Guijuelo y la Fundación Siglo para el Turismo y las Artes de Castilla y León están trabajando en el diseño, la promoción y la señalización de una Ruta del Jamón de Guijuelo con el fin de impulsar el turismo centrado en la gastronomía derivada del cerdo ibérico. La propuesta pública retoma ya algunas iniciativas privadas desarrolladas por empresarios y asociaciones que no han tenido gran repercusión. El consistorio pretende revitalizar la industria, el comercio y la hostelería de la villa a través de las visitas, las catas y las degustaciones.

Como vemos, todas las propuestas señaladas se asientan en la puesta en valor de un patrimonio territorial, construido a lo largo del tiempo, y están orientadas principalmente al turismo con el fin de contribuir a la cohesión social y económica al tiempo que fija la memoria de un saber hacer tradicional.

\section{CONSIDERACIONES FINALES}

La configuración de la identidad colectiva de Salamanca se ha conformado a lo largo de los siglos gracias a la herencia legada por las diversas culturas que habitaron el solar provincial, tanto desde el punto de vista material como intangible, que en la actualidad refuerza el sentido de arraigo y de pertenencia a este territorio de todos los salmantinos. Entre los paisajes agrarios sobresale, la dehesa asociada a la ganadería y, en el caso de estudio al cerdo ibérico, como elemento identitario ligado, además, a los productos derivados del mismo, entre otros al chorizo ibérico que conjuga el saber hacer tradicional con la gestión del monte hueco de quercíneas. Una cultura plasmada también en el arte o en el folklore que hoy es aprovechada como recurso turístico. Resaltamos a modo de conclusión los principales aspectos.

Se han generado unos vínculos del territorio con el patrimonio cultural a partir de la cría del cerdo ibérico, en un sistema agroecológico que respeta el medio natural -la dehesay facilita el aprovechamiento de la carne para la elaboración de embutidos (en concreto el chorizo de carne magra de ibérico) a partir de un saber hacer tradicional transmitido de generación en generación.

Se observa que el modelo de explotación agrosilvopastoril, a través del monte hueco o dehesa, encuentra en las piaras de cerdos ibéricos uno de sus mejores aliados. Más allá del origen de las dehesas y su evolución a lo largo de la historia, en la actualidad se extienden en su mayoría sobre suelos poco aptos para el labrantío, debido al sustrato geológico y a la escasa productividad del suelo donde en ocasiones asoma la roca madre. Los aprovechamientos, hoy como antaño, vienen de la mano de un labrantío en rotaciones largas (hasta de cuatro años) y de los esquilmos de los árboles, con la saca de leña y madera, el ramoneo de las hojas y el vareo de la bellota para el ganado.

La alimentación del ganado porcino con la bellota mediante la montanera, entre finales de septiembre y febrero, trae múltiples beneficios a los propietarios y renteros de las dehesas y, en consecuencia, la cabaña ha incrementado el número de cabezas. Hasta la década de los años sesenta del siglo pasado la raza predominante en las comarcas salmantinas era el cochino ibérico, a partir de la introducción de las denominadas razas mejorantes alóctonas y, por tanto, se empezaron a diferenciar y especificar las denominaciones. No 
obstante, se ha mantenido la raza ibérica en la estructura productiva salmantina dada su rusticidad y la adaptación al medio, a pesar de tener lechigadas inferiores al resto de razas.

Además, el cerdo ibérico no solo ha pervivido por sus características rústicas y por su fácil acomodación al ecosistema adehesado sino porque sus carnes constituyen la materia prima para la elaboración de los embutidos y las chacinas de reconocida calidad en la gastronomía a escala mundial. Hemos señalado como la elaboración de embutidos ha sido una constante histórica en el seno de las familias salmantinas en la época de las matanzas caseras, y como esa labor artesanal ante el incremento de la demanda se ha transferido a las fábricas y a los secaderos. También en algunos casos las chacinas ibéricas eran comercializadas por los arrieros y los choriceros que recorrieron toda la geografía española hasta la modernización de la red viaria y la llegada del ferrocarril a la provincia a finales del siglo XIX.

El modo de vida en torno a la cría del ganado cerdoso ibérico en un sistema extensivo y la fama del chorizo ibérico en particular, ha forjado unos rasgos identitarios asentados en la memoria colectiva de la provincia, que han trascendido a diferentes manifestaciones artísticas: pintura, fotografía, literatura o folklore que evocan precisamente el ciclo anual del cerdo ibérico y los paisajes adehesados, las ferias con la afluencias de ganado o las gentes -choriceros- que vendían las viandas.

Como conclusión final, destacamos que este acervo cultural en la actualidad se pone en valor a partir de un turismo gastronómico, ávido de experiencias, con el fin de contribuir a la cohesión social, económica y territorial salmantina. Ferias, museos,... son en este sentido las nuevas apuestas.

\section{BIBLIOGRAFÍA}

CABERO DIÉGUEZ, V. (2004): Iberismo y Cooperação. Passado e futuro da Península Ibérica. Guarda, Centro de Estudos Ibéricos, Câmara Municipal de Guarda.

CABO ALONSO, A. (1960): «La ganadería española. Evolución y tendencias actuales», Estudios Geográficos $\mathrm{n}^{\mathrm{0}}$ 70, pp. 33-34.

CABO ALONSO, A. (1978): «Antecedentes históricos de las dehesas salmantinas», en Estudio integrado y multidisciplinario de la dehesa salmantina. 1, Estudio fisiográfico-descriptivo. $2^{\circ}$ fasc. Salamanca, Centro de Edafología y Biología Aplicada de Salamanca y Centro Pirenaico de Biología Experimental de Jaca. Jaca, pp. 63-98.

CABO ALONSO, A. (1993): «La cabaña española en el último medio siglo», en Coloquio sobre Geografía Agraria, en Gil Olcina, A. y Morales Gil, A. (Eds.). Medio siglo de cambios agrarios en España. Alicante, Diputación Provincial de Alicante, Instituto de Cultura "Juan Gil-Albert", pp. 115-149.

DÍAZ, J. (2005): Estampas de ferias y mercados (siglos XVIII-XX). Valladolid, Edición digital Fundación Saber.es.

GÓMEZ GUTIÉRREZ, J.M. (Coord.) (1991): El libro de las dehesas. Salamanca, Consejería de Medio Ambiente y Ordenación del Territorio. Junta de Castilla y León.

GÓMEZ PELLÓN, E. (2005): «La extraña seducción de la costumbre: la estampa costumbrista como síntesis de sueño y realidad», en Estampas de ferias y mercados (siglos $X V I I I-X X)$. Valladolid, Edición digital Fundación Saber.es 
JUNTA DE CASTILLA Y LEÓN (2017): Anuario de Estadística Agraria de Castilla y León, 2015. Valladolid, Consejería de Agricultura y Ganadería.

KENT, C. (2008a): Estampas de la ciudad de Salamanca. Salamanca, Ed. EDIFSA.

KENT, C. (2008b): El perfil de Salamanca. Historia fotográfica de una seña de identidad. Salamanca, Ed. GRUPOSA, S. A. La Gaceta de Salamanca y Junta de Castilla y León.

KLEIN, J. (1960): «La ganadería española. Evolución y tendencias actuales», Estudios Geográficos n ${ }^{\circ} 70$, pp. 33-34.

LLOPIS, S. (1965): Ensayo de una historia del comercio salmantino. Salamanca, Gráficas Cervantes, S. A.

LLORENTE MALDONADO DE GUEVARA, A. (1980): Las Comarcas Históricas y Actuales de la Provincia de Salamanca. Salamanca, Centro de Estudios Salmantinos.

LLORENTE PINTO, J.M. (1985). Los paisajes adehesados salmantinos. Salamanca, Centro de Estudios Salmantinos.

LLORENTE PINTO, J.M. (1993): «Dificultades para la gestión y el aprovechamiento integral en las dehesas salmantinas», Salamanca. Revista de Estudios, $\mathrm{n}^{\circ}$ 31-32, pp. 207-222.

MADOZ, P. (1845-1850): Diccionario geográfico-estadístico-histórico de España y sus posesiones de ultramar. Madrid. Salamanca, Edición facsimil de Ámbito ediciones, 1984.

MAS, J. (1922): El rastrero. Madrid, editorial Rivadeneyra.

MINISTERIO DE AGRICULTURA (1978): Comarcalización Agraria de España. Madrid, Servicio de Publicaciones Agrarias.

MINISTERIO DE AGRICULTURA, ALIMENTACIÓN Y MEDIO AMBIENTE (2013): Caracterización de las Comarcas Agrarias. Madrid, Provincia de Salamanca. Tomo 39.

MINISTERIO DE MEDIO AMBIENTE Y MEDIO RURAL Y MARINO (2010): Catálogo Oficial de Razas de Ganado de España. Madrid.

MORALES GUERRERO, A. y MORALES GUERRERO, P. (2000): «Análisis económico de los recursos productivos de las dehesas salmantinas», en $7^{\circ}$ Congreso de Economía Regional, Soria, pp. 362-378.

ORTEGA VALCÁRCEL, J. (1998): «El patrimonio territorial: el territorio como recurso cultural y económico», Ciudades, no 4, pp. 38-40.

RUIZ ANSEDE, T. (1992): Cándido Ansede, fotógrafo de Salamanca. Con la opinión coloreada Franja Fotográfica. Salamanca, Junta de Castilla y León.

SEPULVEDA, E. (1887): La vida en Madrid en 1886. Madrid, Libr. Fernando Fe.

TEJERO de la CUESTA, J.M. (Coord.) (1988): Análisis del medio físico de Salamanca. Delimitación de unidades y estructura territorial. Valladolid, Consejería de Fomento.

TOLOSA SOLA, L. (1998): El cerdo ibérico. Crianza y elaboración. Barcelona, Gráficas Colorama,

WANDERER (1899): «Una república dentro de España. Candelario, el país de los chorizos», Alrededor del Mundo, Imprenta y Litografía de Henrich y C. ${ }^{a}$, Barcelona, Año I, $\mathrm{n}^{\circ} 5,7$ de julio de 1899 . 